\title{
Oral health status among the adult tobacco users in a selected rural area of Bangladesh
}

\author{
Kabir S1, Sultana N², Rahman M M³
}

Received: 23.07.2017

Accepted: 29.08 .2017

Abstract:

Tobacco use is a primary cause of many oral diseases and adverse oral conditions and it is a risk factor for oral cancer, periodontal diseases, congenital defects such as cleft lip and palate in children whose mother smokes during pregnancy. A cross sectional study was conducted among 190 adult tobacco users in Charpaterdoho Union, Madarganj Upazilla, Jamalpur District, during the period from July 2013 to December 2013 to assess the oral health status of the adult tobacco users in rural area of Bangladesh. Data were collectedby using pre tested interview administered questionnaire andto assess the oral health status intra oral examination was performed by a dental surgeon assisted by two trained and calibrated investigators. Both descriptive and inferential statistics has been used for analysis of data with the help of Statistical Package for Social Science SPSS (Version 21) software on the basis of different variables. The study result revealed that out of 190 respondents maximum 61 (32.1\%) belongs to 18-28 years age group, majority $116(61.1) \%$ were male. Among the respondents tobacco used in different ways like cigarette, 'Gul', 'Zorda', betel leaf, 'Sadapata' consumption where cigarette was the commonly used form of tobacco and the least commonly used form of tobacco was betel leaf and 'Sadapata'. In intra oral examination this study result revealed that around 50 (26\%) respondents dentition condition was healthy, and 121 (63.7\%) respondents had less than 25\% decayed teeth, 115(60.5\%) respondents had periodontitis, around less than three fourth 132 (69.5\%)had gingivitis, almost all (95.3\%) had dental deposition or plaque and 155 (81.6\%) respondents had no functional prosthesis. In logistic regression analysis monthly family income level ( $p=.004)$ was significantly associated with oral health status when the adjusted with other variables (education, sex, age). Sex and age were not associated with oral health status. Exposure to tobacco is a significant, modifiable risk factor for different oral diseases, so the changing attitude can be occurred by giving adequate information and motivation to the mass people along with dental health education.

Key words:Tobacco, Oral disease, Periodontitis.

1. Dr. Shahria Kabir, Dental Surgeon, Jorapukur Oral and Dental Health Center, Khilgaon, Dhaka.

2. Dr. Nihar Sultana, Assistant Professor, Department of Oral Anatomy and Physiology, Mandy Dental College, Dhaka; PhD Research Fellow ( Bangladesh University of Professionals).

3. Dr. Md. Mahfuzur Rahman, Dental Surgeon, S.F. Dental Surgery, Mirpur, Dhaka.

\section{Correspondence :}

Dr. Nihar Sultana, Assistant Professor, Department of Oral Anatomy and Physiology, Mandy Dental College \& Hospital, PhD Research Fellow (BUP), Phone: 01712-843965, E-mail: nihard40@gmail.com 


\section{Introduction:}

The use of tobacco is a major public health threat all over the world. According to WHO estimates, nearly one third of the global adult population 1.1 billion people, of whom 200 million are female (nearly $47 \%$ of men and $12 \%$ of women user). In developing countries, $48 \%$ of men and $7 \%$ of women smoke while in developed countries $42 \%$. Consumption level ranges between $55 \%$ and $80 \%$ among adult men and 3\% and $71 \%$ among women ${ }^{[1]}$. Tobacco use is a primary cause of many oral diseases and adverse oral conditions and it is a risk factor for oral cancer, oral cancer recurrence, adult periodontal diseases, congenital defects such as cleft lip and palate in children whose mother smokes during pregnancy. Tobacco use suppresses the immune system's response to oral infection, retards healing following oral surgical and accidental wounding, promotes periodontal degeneration in diabetics and adversely affects the cardiovascular system.Oral and pharyngeal cancers pose a special challenge to oral health programmes particularly in developing countries. Cancer of the oral cavity is high among men, where oral cancer is the eighth most common cancer in the world. Incidence rates of oral cancer are high in developing countries, particularly in areas of South Central Asia where cancer of the oral cavity is among the three most frequent types of cancer ${ }^{[2-4]}$. World wide tobacco use among the adult is associated with a high risk of oral health problem. The adult groups are conceded as the important population of the country and prevalence of tobacco use particularly in recent year had an increasing trend in this age group especially among the adult population. The aim of this cross sectional study was to assess the oral health status of the adult tobacco users in rural area of Bangladesh which covers the pattern of tobacco uses with duration and daily consumption, the association between oral health status with other socio-demographic variables.

\section{Materials and methods:}

A cross sectional study was conducted among purposively selected 190 adult tobacco users in Charpaterdoho Union, MadarganjUpazilla, Jamalpur District, for the duration of July 2013 to December 2013. The study was approved by the Institutional Review Board of the Bangladesh University of Health Sciences and official permission for data collection was obtained from the Chairman of Charpaterdoho Union Parishad. The inclusion criteria set were tobacco user both smoking and smokeless tobacco aged between 18 and 65 years, living in the study area and who were mentally compromised or terminally ill were excluded from the study. Prior taking verbal informed consent from each respondents data were collected by pre tested interview administered questionnaire and intra oral examination assisted by two trained and calibrated investigators guided by a dental surgeon. The data collection places were different public places in Charpaterdoho union like different points in local bazar, school area, college area and from mosque area specially after namaz in Friday. Oral health status was assessed with dentition condition, periodontal condition, oral mucosa and gingival condition, dental deposition/plaque and tartar, functional prosthesis related variables. Dentition condition in this study assessed by considering total number of present teeth as $100 \%$, the percentage of decayed teeth was calculated, here missing teeth was not counted and functional prosthesis in this study refers to any removable or fixed prosthesis using by the respondents like denture, crown, bridge. Finally data analysis was carried out using the software Statistical Package for Social Science (SPSS) 21 version on the basis of objectives of the study and data presentation was done by MS Word and MS Excel.Oral health status associated with other socio-demographic variables were explored by binary logistic regression analysis, where the value of less than 0.05 was considered to be statistically significant. 
Results:

Table 1: Socio demographic characteristics of the respondents. [ $n=190]$

\begin{tabular}{|c|c|c|}
\hline Age group (in years) & Frequency & Percentage \\
\hline $18-28$ & 61 & 32.1 \\
\hline $29-38$ & 39 & 20.5 \\
\hline $39-48$ & 40 & 21.1 \\
\hline Above 48 & 50 & 26.3 \\
\hline Mean $( \pm S D)$ & \multicolumn{2}{|c|}{$41.3( \pm 6.81)$} \\
\hline Educational qualification & Frequency & Percentage \\
\hline Illiterate & 40 & 21.0 \\
\hline Up to Primary & 50 & 26.3 \\
\hline Up to HSC & 68 & 36.0 \\
\hline Graduation and above & 32 & 16.8 \\
\hline Religion & Frequency & Percentage \\
\hline Islam & 179 & 94.2 \\
\hline Hindu & 11 & 5.8 \\
\hline Occupation & Frequency & Percentage \\
\hline Service & 51 & 27.2 \\
\hline House wife & 45 & 23.9 \\
\hline Day labor & 31 & 16.3 \\
\hline Business and others & 63 & 33.4 \\
\hline Monthly family income (in taka) & Frequency & Percentage \\
\hline Up to 10000 & 83 & 43.6 \\
\hline $10001-15000$ & 43 & 22.6 \\
\hline Above 15000 & 64 & 33.7 \\
\hline Mean $( \pm S D)$ & \multicolumn{2}{|c|}{$12397.2( \pm 2976.3)$} \\
\hline
\end{tabular}

Table 1 revealed that the mean age of the respondents was $41.3 \pm 6.81$ years, $68(36.0 \%)$ respondents educational qualification was up to HSC, 179 (94.2\%) were Muslim, 63 (33.4\%) respondents occupation was business and others, the mean monthly family income of the respondents was $12397.2( \pm 2976.3)$ taka.

Figure 1: Distribution of the respondents according to sex.

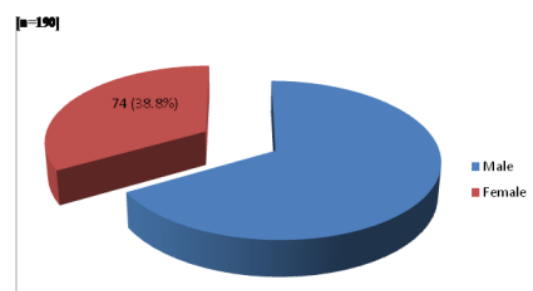

Figure 1 shows out of 190 respondents 116 (61.1) \% were male and 74 (38.8) \% were female.
Figure 2: Distribution of the respondents according to different ways of tobacco use. [ $n=190]$

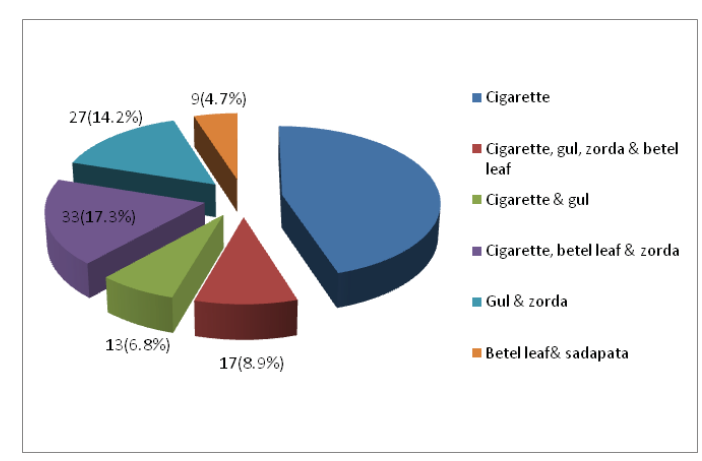

Figure 2 shows 81 (42.6\%) use tobacco in the form of cigarette, where as $9(4.7 \%)$ use tobacco in the form of betel leaf andsadapata.

Table 2 : Distribution of the respondents according to consumption of different types of tobacco per day.

\begin{tabular}{|c|c|c|c|}
\hline \multicolumn{2}{|c|}{$\begin{array}{c}\text { Different types of tobacco } \\
\text { consumption per day }\end{array}$} & Frequency & Percentage \\
\hline \multirow{3}{*}{ Cigarette } & Up to 5 stick & 60 & 31.5 \\
\cline { 2 - 4 } & $6-10$ stick & 26 & 13.6 \\
\cline { 2 - 4 } & More than 10 stick & 30 & 15.7 \\
\cline { 2 - 4 } & No response & 74 & 38.9 \\
\hline \multirow{3}{*}{ Gul } & Less than $3 \mathrm{gm}$ & 7 & 3.7 \\
\cline { 2 - 4 } & $3-5 \mathrm{gm}$ & 1 & 0.5 \\
\cline { 2 - 4 } & No response & 182 & 95.8 \\
\hline \multirow{3}{*}{ Zorda } & Less than $3 \mathrm{gm}$ & 70 & 36.8 \\
\cline { 2 - 4 } & $3-5 \mathrm{gm}$ & 22 & 11.6 \\
\cline { 2 - 4 } & No response & 98 & 51.6 \\
\hline
\end{tabular}

Table 2 shows 60 (31.5\%) take up to 5 cigarette per day, 26 (13.6\%), 30 (15.7\%) take 6-10 cigarettes, more than 10 cigarettes per day respectively. About daily zorda consumption $70(36.8 \%), 22(11.6 \%)$ take less than $3 \mathrm{gm}, 3-5 \mathrm{gm}$ respectively.

Table 3 : Distribution of the respondents according to duration of tobacco use.

\begin{tabular}{|c|c|c|}
\hline Duration of tobacco use & Frequency & Percentage \\
\hline Less than 1 year & 37 & 19.4 \\
\hline $1-5$ year & 64 & 33.6 \\
\hline More than 5 years & 89 & 46.8 \\
\hline Total & 190 & 100.0 \\
\hline
\end{tabular}

Table 3 shows 89 (46.8\%) respondents use tobacco for the duration of more than 5 years, 64 (33.6\%) and $37(19.4 \%)$ use tobacco for the duration of $1-5$ years 
and less than 1 year respectively.

Table 4 : Distribution of the respondents according to the oral health status.

\begin{tabular}{|c|c|c|}
\hline \multicolumn{2}{|c|}{ Oral health status } & $\mathbf{n}(\%)$ \\
\hline \multirow{3}{*}{ Dentition condition } & Healthy & $50(26.3 \%)$ \\
\cline { 2 - 3 } & More than 50\% decayed teeth & $10(5.3 \%)$ \\
\cline { 2 - 3 } & Less than 50\% \& more than 25\% decayed teeth & $9(4.7 \%)$ \\
\cline { 2 - 3 } & Less than 25\% decayed teeth & $121(63.7 \%)$ \\
\hline \multirow{2}{*}{$\begin{array}{c}\text { Periodontal } \\
\text { condition }\end{array}$} & Healthy periodontium & $75(39.5 \%)$ \\
\cline { 2 - 3 } $\begin{array}{c}\text { Oral mucosa and } \\
\text { gingival condition }\end{array}$ & Periodontitis & $115(60.5 \%)$ \\
\cline { 2 - 3 } & Healthy oral mucosa & $46(24.2 \%)$ \\
\hline \multirow{2}{*}{$\begin{array}{c}\text { Dental deposition / } \\
\text { plaque and tartar }\end{array}$} & Gingivitis & $132(69.5 \%)$ \\
\hline \multirow{2}{*}{$\begin{array}{c}\text { Functional } \\
\text { prosthesis }\end{array}$} & Presence of oral lesion & $12(6.3 \%)$ \\
\cline { 2 - 3 } & Absent & $181(95.3 \%)$ \\
\hline
\end{tabular}

Table 4 shows about the dentition condition of the respondents 121 (63.7\%) had less than 25\% decayed teeth, where as 50 (26.3\%) dentition condition was healthy. $115(60.5 \%)$ had periodontitis and $75(39.5 \%)$ had healthy periodontium, about oral mucosa and gingival condition 132 (69.5\%) had gingivitis, 181 (95.3\%) had dental deposition / plaque and tartar, 35 (18.4\%) had functional prosthesis.

Table 5: Oral health status associated with other socio-demographic variables explored by logistic regression analysis

\begin{tabular}{|c|c|c|c|}
\hline $\begin{array}{c}\text { Socio-demographic } \\
\text { variables }\end{array}$ & $\mathbf{B}$ & Sig (p values) & $\operatorname{Exp(B)}$ \\
\hline Education & -.227 & .312 & .797 \\
\hline Occupation & .404 & .238 & 1.498 \\
\hline $\begin{array}{c}\text { Monthly family } \\
\text { income }\end{array}$ & -1.222 & .004 & .295 \\
\hline Sex & -1.383 & .066 & .251 \\
\hline Age & .467 & .065 & 1.596 \\
\hline
\end{tabular}

Table 5 shows that monthly family income level (p $=.004$ ) was significantly associated with oral health status when the adjusted with other variables(education, sex, age). Sex and age were not associated with oral health status ( $p$ values $.066, .065$ respectively). Education and occupation was not associated with oral health status ( $p$ values $.312, .238$ respectively).

\section{Discussion:}

This cross sectional study was carried out with the aim to assess the oral health status of the adult tobacco users in rural area of Bangladesh which covers the pattern of tobacco uses with duration and daily consumption, the association between oral health status with other socio-demographic variables. According to the study results the mean age, mean monthly family income ofthe tobacco users was 41.3 \pm 6.81 years, $12397.2( \pm 2976.3)$ taka respectively,68 $(36.0 \%)$ respondents educational qualification was up to HSC, 179 (94.2\%) were Muslim, 63 (33.4\%) respondents occupation was business and others. A study from Department of Public Health Dentistry, Yenepoya Dental College, Deralakatte, Mangalore, India, ${ }^{[5]} 7.8 \%$ among males, prevalence of mucosal lesions was highest in the 46-60 year-old followed by the $\geq 61$ year age group while among females, prevalence was highest in the 31-45 years old followed by the 46-60 years age group. In this study, 190 respondents maximum $61(32.1 \%)$ belongs to $18-28$ years age groups and $116(61.1) \%$ subject are male, $74(38.8 \%)$ are female.According to different studies occurred on Bangladesh, India, Pakistan, their distribution of tobacco consumption is not uniform; it is disproportionately higher in lower socioeconomic groups, poor, semi-skilled manual occupation groups, unemployed and poor educational achievers ${ }^{[6-11]}$, which was much consistent with the socio-demographic results of this study. Gender and locality differences in tobacco prevalence among adult Bangladeshi population a study showed where current smoking and gul usage were significantly higher in males $(42.2 \%)$ than females $(2.3 \%)$ while chewing tobacco was more common in females $(21.6 \%)$ than males (19.4\%). On average a smoker consumed 9.3 sticks a day with males ${ }^{[11]}$, which also supports this study result where 81 (42.6\%) consumed cigarette as a form of using tobacco, male respondents were in $116(61.1 \%)$ (Fig 1) and 60 (31.5\%) respondents were uses less than 5 stick per day. In intra oral examination this study result revealed that around 50 (26\%) respondents dentition condition was healthy, and 121 $(63.7 \%)$ respondents have less than $25 \%$ decayed teeth, 115 ( $60.5 \%)$ respondents had periodontitis , around $70 \%$ respondents had gingivitis, almost all the respondents $181(95.3 \%)$ had dental deposition or plaque and in $155(81.6 \%)$ respondents functional prosthesis were absent. In this study, income level ( $p$ $=.004$ ) washighly significantly associated with oral health when the adjusted with other variables (education, sex, age). Sex and age were not associated with 
oral health, although in this study maximum subjects were male and 18-28 years age group which also supports the study results. ${ }^{[5]}$ This study was conducted with a small sample population and DMFT score was not assessed in this study which was a limitation of the study.

\section{Conclusion:}

Along with previous research,based on findings from this study, it can be concluded that tobacco consumption is a major risk factor for different oral diseases including periodontitis and non-smoking tobacco consumption like chewing betel leaf with tobacco leaf and taking gul may be more harmful for oral health in rural Bangladesh. Exposure to tobacco is a significant, modifiable risk factor for tooth loss, current decay and periodontal disease in older adults, independent of selected social and behavioral risk factors. A large proportion of adult periodontitis may be preventable through prevention and cessation of chewing betel leaf and taking Gul. Major oral and dental problem initiated by consumption on tobacco related product specially chewing tobacco leaf and betel nut etc. The changing attitude can be occurred by giving adequate information and motivation to the mass people. So dental health education is needed focusing on special needs of population to improve their quality of life expectancy.

\section{References :}

1. Morshed M, Tobacco Situation in Bangladesh ; Yearly health situation report, IEDCR-2000. 2-9.

2. Jensen EJ and Overgaard E. Smoking patterns, knowledge of tobacco related health effects and desires to quit am006Fng 14-17- year-old boarding school pupils in Denmark, 1987-90. Tob.Control 1993; 2: 296-99

3. Jiloha CR. Biological basis of tobacco addiction: Implications for smoking-cessation treatment Indian J Psychiatry. 2010 Oct-Dec; 52(4): 301-307. doi: 10.4103/00195545.74303.

4. Reibel J. Tobacco and oral diseases. Update on the evidence, with recommendations. Medical principles and practice 2003; 12:22-32

5. Shenoy RP, ShettyMS, ShenaiKP, KotianMS: Evaluation of Oral Status and Tobacco Use in a Rural Population and Testing a Scale Developed to Rate Oral Status: a Pilot Study

6. Gupta PC, Ray CS. Smokeless tobacco and health in India and South Asia. Respirology 2003;8:419-31.
7. Efroymson D, Ahmed S. Building momentum for tobacco control: the case of Bangladesh. In: de Beyer J, Brigden L W, editors. , eds. Tobacco control policy. strategies, success and setbacks Washington DC: World Bank and Research for International Tobacco Control (RITC), 2003:13-37.

8. Bangladesh Bureau of Statistics Prevalence of smoking in Bangladesh, November 1995 Dhaka: BBS, 1996.

9. Bangladesh Bureau of Statistics Report of survey on prevalence of morbidity, treatment status, treatment expenditures, fertility, immunization and smoking, July 1997 Dhaka: BBS, 1999.

10. Rahman M, Rahman M, Flora MS, et al. Behavioural risk factors of non-communicable diseases in Bangladesh Dhaka, 2006.

11. Qidwai W, Saleheen D, Saleem S, et al. Are our people health conscious? Results of a patients survey in Karachi, Pakistan. J Ayub Med Coll Abbottabad 2003;15:10-3. 